\title{
Potential contribution of leisure activity to the energy expenditure patterns of sedentary populations
}

\author{
BY M. B. E. LIVINGSTONE ${ }^{1}$, J. J. STRAIN ${ }^{1}$, A. M. PRENTICE ${ }^{2}$, W. A. COWARD ${ }^{2}$, \\ G. B. NEVIN ${ }^{1}$, M. E. BARKER ${ }^{1}$, R. J. HICKEY ${ }^{1}$, P. G. MCKENNA ${ }^{1}$ \\ AND R. G. WHITEHEA D ${ }^{2}$ \\ ${ }^{1}$ Biomedical Sciences Research Centre, University of Ulster, Jordanstown, Newtownabbey, \\ Co. Antrim BT37 OQB, Northern Ireland \\ ${ }^{2}$ Medical Research Council, Dunn Nutritional Laboratory, Downham's Lane, Milton Road, \\ Cambridge CB4 $1 X J$
}

(Received 26 July 1990 - Accepted 2I September 1990)

\begin{abstract}
Total daily energy expenditure (TEE) by the doubly-labelled $\left({ }^{2} \mathrm{H}_{2}{ }^{18} \mathrm{O}\right)$ water method and basal metabolic rate (BMR) by indirect calorimetry were measured in thirty-two healthy free-living adults in Northern Ireland. Habitual physical activity patterns in occupational and discretionary activities were assessed by interview questionnaire. Expressed as a multiple of BMR the TEE values for the sixteen males (1.88 (SD 0.28), range 1.44-2.57) and sixteen females (1.77 (SD 0.16), range 1.50-2.06) were compatible with current Department of Health and Social Security (DHSS; 1979) and Food and Agriculture Organization/World Health Organization/United Nations University (FAO/WHO/UNU; 1985) estimates of energy requirements. The results suggest that discretionary physical activity is now emerging as an equally important determinant of energy expenditure in the UK as the occupational classifications currently used as the basis of DHSS (1979) and FAO/WHO/UNU (1985) recommendations for energy requirements. Therefore, realistically achievable inputs of recreational exercise can have a significant impact in counteracting low levels of energy expenditure which are associated with modern lifestyles and are implicated as a risk factor for coronary heart disease and obesity.
\end{abstract}

Leisure activity : Energy expenditure: Sedentary populations

In recent years increased mechanization in the workplace and the home has resulted in a marked trend towards very low levels of energy expenditure (Prentice et al. 1985). As a result predominantly sedentary populations can now achieve energy equilibrium at a level below that considered optimal for health. These secular changes have highlighted the importance of regular recreational exercise to overall health status, particularly in relation to coronary heart disease (CHD) and obesity. In the future, as lifestyles become increasingly leisure centred, recreational physical activity is likely to assume an even greater importance. Although vigorous efforts are currently being made to promote sport and active recreation there has been no systematic investigation of the real significance of discretionary physical activity in determining energy expenditure. There remains some doubt as to whether realistically achievable levels of exercise, compatible with modern lifestyles, can have any significant impact.

In the present study total energy expenditure (TEE) measured by the doubly-labelled $\left({ }^{2} \mathrm{H}_{2}{ }^{18} \mathrm{O}\right)$ water method (DLW) in healthy free-living subjects and assessment of their patterns of physical activity by questionnaire have demonstrated that recreational activity has now emerged as the key determinant of energy expenditure in most sedentary people. The results suggest that reasonable levels of leisure-time activity can have an important 
effect on overall energy expenditure and might, therefore, be beneficial to health. The findings also suggest that classification of people according to discretionary activity may be at least as important as the occupational criteria currently used as the basis of Department of Health and Social Security (DHSS; 1979) and Food and Agriculture Organization/ World Health Organization/United Nations University (FAO/WHO/UNU; 1985) recommendations for energy requirements.

\section{METHODS}

\section{Subjects}

Thirty-two subjects (sixteen male, sixteen female) were each recruited by letter and followup interview from districts around and including the greater Belfast area. All subjects had previously participated in the Northern Ireland Diet and Health Study and were selected to represent the entire range of energy intakes as assessed in that study by the $7 \mathrm{~d}$ weighed inventory technique (Barker et al. 1989).

All subjects were non-smokers and were not taking any drugs or medication which might influence metabolism. None of the female subjects was taking oral contraceptives or was pregnant. One female subject (no. 2) was lactating (18 months post partum). The occupational and physical characteristics of the subjects are presented in Table 1 . The cohort included a wide range of full- and part-time occupations, socio-economic groups, ages and body-weights. Three male subjects (nos. 1, 4,7) and two female subjects (nos. 1 , 4) were in full-time manual employment but otherwise the majority of occupations involved predominantly sedentary activity.

Ideal body-weight (IBW) was defined as that corresponding to the mid-point of the weight range for medium frame size reported in the weight-for-height tables of the Metropolitan Life Insurance Company (1983).

The trend was towards adiposity, nine of the male subjects and seven of the female subjects had body-weights $>110 \% \mathrm{IBW}$ and one male subject and two female subjects met the criteria for obesity ( $>135 \%$ IBW).

The study was approved by the Queen's University Ethical Committee, Belfast.

\section{Basal metabolic rate $(B M R)$}

BMR was measured under standard conditions: in a comfortably warm room, lying at complete rest and fasted $(13 \mathrm{~h})$. Immediately upon awakening respiratory gas exchange rates were measured at 1 min intervals for $40 \mathrm{~min}$ with a Mijnhardt Oxycon-4/Apple II Computer Test System interfaced with a dry gas meter paramagnetic oxygen analyser, infra-red carbon dioxide analyser and electronic microprocessor system (Cardiokinetics Ltd, Medical Diagnostic Instrumentation, Salford). Expired air was collected with a twoway non-rebreathing valve and nose clip (Hans Rudolp Inc., Kansas City, Mo). Gas volumes were corrected to standard temperature and pressure and energy values were determined from $\mathrm{O}_{2}$ consumption using the Weir (1949) formula. One male subject (no. 4) was unable to have his BMR measured directly and this was calculated from standard equations based on weight (FAO/WHO/UNU, 1985).

\section{The DLW method}

The DLW method assesses $\mathrm{CO}_{2}$ production rate from the differential disappearance of the stable isotopes deuterium and ${ }^{18} \mathrm{O}$ following an oral loading dose. TEE is calculated from $\mathrm{CO}_{2}$ production using classical respirometry formulas in which values for the respiratory quotient (RQ) are derived from the composition of the diet (Black et al. 1986). The method provides a measure of energy expenditure integrated over the entire measurement period 


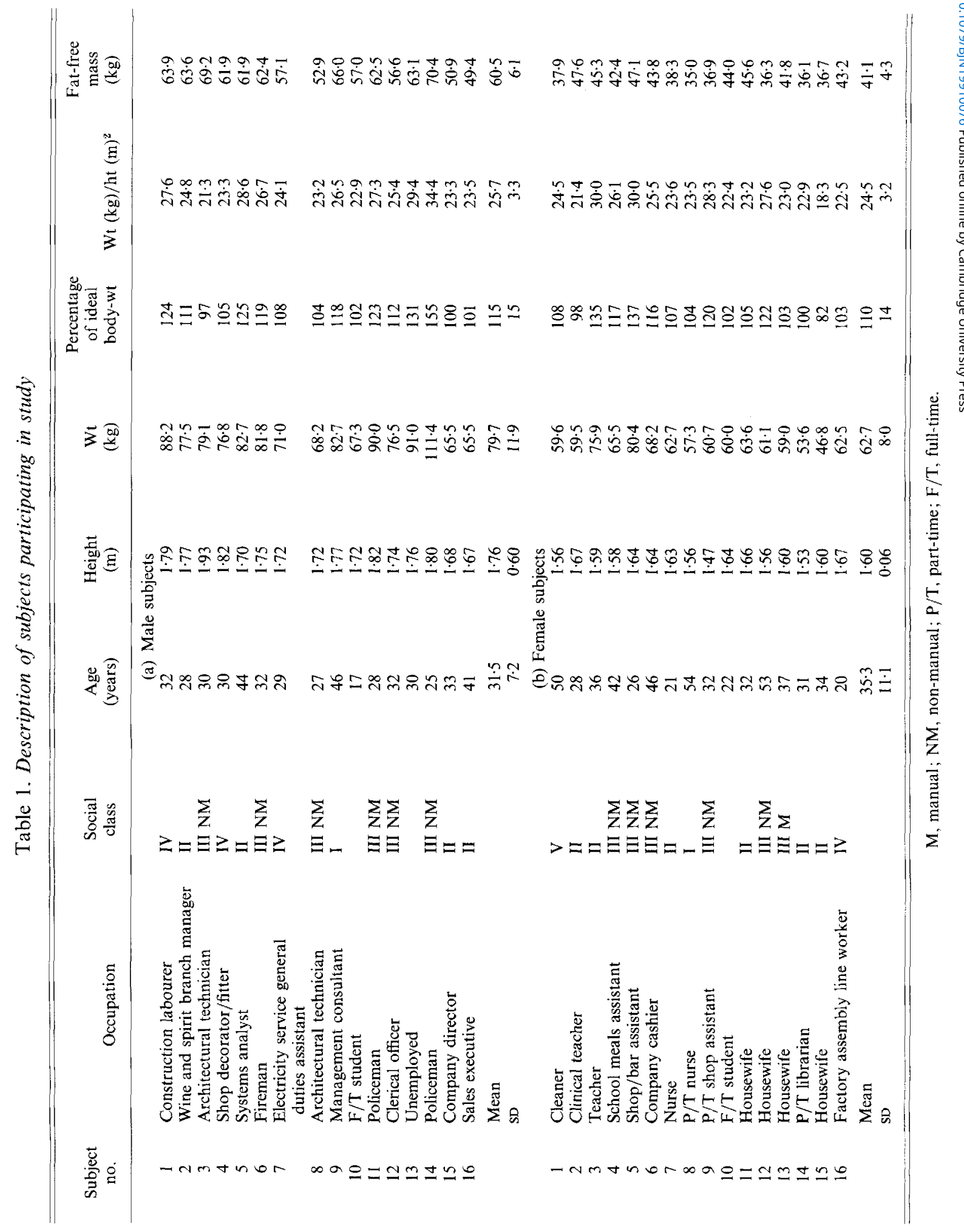


( $15 \mathrm{~d}$ in the present study). It is safe, non-invasive and non-intensive since subjects merely drink the initial dose and collect a mid-morning urine sample on subsequent days. Ten cross-validation studies involving forty-nine subjects in several different laboratories indicate that the method is accurate to $\pm 2-3 \%$ (Coward, 1988; Schoeller, 1988). Levels of precision depend on the exact methodology employed, but have been estimated to be better than $\pm 5 \%$ in this laboratory under optimal conditions (Coward et al. 1988; Prentice, 1988).

The exact protocol used in the present study was identical to that used in several previous studies and is described in detail elsewhere together with methods of analysis, calculation of results, fractionation and RQ assumptions, and estimates of error (Prentice et al. 1986; Coward, 1988; Coward et al. 1988; Prentice, 1988). The method for predicting the percentage of water turnover subject to isotopic fractionation yielded 29 (SD 5) for men and 32 (SD 6) for women in this group. Propagation of error analysis yielded an average standard error for the estimates of TEE of $6 \cdot 0 \pm 2.9 \%$.

Body fat content was calculated from total body water by assuming that fat-free mass has a water content of $730 \mathrm{~g} / \mathrm{kg}$.

\section{Physical activity patterns}

An interview questionnaire was used to assess the nature and duration of habitual physical activity patterns in occupational and discretionary activities. Discretionary activities included all leisure-time activities associated with household tasks such as gardening, socially desirable activities such as community activities, and activities for the promotion of cardiorespiratory efficiency (FAO/WHO/UNU, 1985). Occupational and discretionary activities were subsequently classified as light, moderate or high intensity according to FAO/WHO/UNU (1985) criteria. Crude activity scores representing the number of hours per week spent at moderate activity levels were assigned to each subject. Time spent at high activity levels was doubled in this calculation. Each subject's activity score consisted of two components representing occupational and discretionary activities.

\section{RESULTS}

Table 2 lists the estimates of TEE and BMR for all subjects. Average TEE of the men $(14.23$ (SD 2.95) $\mathrm{MJ} / \mathrm{d}$ ) was $44 \%$ greater than in the women $(9.87$ (SD 1.49$) \mathrm{MJ} / \mathrm{d}$ ), although mean body-weight was only $27 \%$ greater. Both groups exhibited an approximately twofold range in TEE: $9.36-21.71 \mathrm{MJ} / \mathrm{d}$ in the men and $7.51-12.38 \mathrm{MJ} / \mathrm{d}$ in the women. Expressing TEE as a multiple of BMR for each subject automatically corrects for differences in lean body mass since this is the most important determinant of BMR. The values for TEE:BMR, sometimes termed the physical activity index (PAI), therefore allow a direct comparison of activity patterns since confounding variables such as height, weight, sex and age have largely been removed. In the present study the mean PAI values were 1.88 (SD 0.28) for the men and 1.77 (SD 0.16) for the women. Compared with current FAO/WHO/UNU (1985) recommendations (Fig. 1), only two male and two female subjects had TEE values which fell short of the estimates for light activity occupations but were still above the suggested maintenance requirement of 1.4 times BMR. Furthermore, ten males and twelve females were expending energy compatible with the estimated requirements for moderate and heavy activity occupations even though their occupational status suggests that many of these subjects would have lower energy expenditures. Current DHSS (1979) recommendations are expressed in absolute terms and work out to be about 1.65 for men and 1.70 for women who are moderately active. Applying these criteria also confirms that eleven males and eleven females were more than moderately active. 
Table 2. Energy expenditure of healthy free-living subjects measured by indirect calorimetry and double-isotope technique

\begin{tabular}{|c|c|c|c|c|}
\hline $\begin{array}{c}\text { Subject } \\
\text { no. }\end{array}$ & $\begin{array}{c}\text { Basal } \\
\text { metabolic } \\
\text { rate } \\
(\mathrm{MJ} / \mathrm{d})\end{array}$ & $\begin{array}{l}\text { Total energy } \\
\text { expenditure } \\
(\mathrm{MJ} / \mathrm{d})\end{array}$ & $\begin{array}{c}\text { Total energy } \\
\text { expenditure } \div \\
\text { basal metabolic } \\
\text { rate }\end{array}$ & $\begin{array}{c}\text { Total energy } \\
\text { expenditure- } \\
\text { basal metabolic } \\
\text { rate } \\
(\mathrm{MJ} / \mathrm{d})\end{array}$ \\
\hline \multicolumn{5}{|c|}{ (a) Male subjects } \\
\hline 1 & $8 \cdot 43$ & $21 \cdot 71$ & $2 \cdot 57$ & 13.28 \\
\hline 2 & $7 \cdot 39$ & $16 \cdot 52$ & $2 \cdot 24$ & $9 \cdot 13$ \\
\hline 3 & $7 \cdot 13$ & $15 \cdot 24$ & $2 \cdot 14$ & $8 \cdot 11$ \\
\hline 4 & $7 \cdot 73^{*}$ & 16.08 & $2 \cdot 08$ & $8 \cdot 35$ \\
\hline 5 & $7 \cdot 56$ & $15 \cdot 38$ & $2 \cdot 03$ & $7 \cdot 82$ \\
\hline 6 & $7 \cdot 59$ & $15 \cdot 18$ & $2 \cdot 00$ & $7 \cdot 60$ \\
\hline 7 & 7.03 & 13.98 & 1.99 & $6 \cdot 95$ \\
\hline 8 & $6 \cdot 68$ & $12 \cdot 44$ & 1.86 & $5 \cdot 75$ \\
\hline 9 & $7 \cdot 34$ & $13 \cdot 27$ & 1.81 & 5.93 \\
\hline 10 & $7-23$ & 13.00 & 1.80 & 5.78 \\
\hline 11 & $7 \cdot 87$ & $13 \cdot 16$ & 1.67 & $5 \cdot 29$ \\
\hline 12 & $6 \cdot 71$ & $11 \cdot 17$ & 1.66 & $4 \cdot 46$ \\
\hline 13 & $9 \cdot 50$ & $15 \cdot 62$ & 1.64 & $6 \cdot 12$ \\
\hline 14 & $9 \cdot 67$ & 15.69 & 1.62 & 603 \\
\hline 15 & $6 \cdot 30$ & $9 \cdot 36$ & 1.49 & $3 \cdot 05$ \\
\hline 16 & 6.84 & $9 \cdot 87$ & $1 \cdot 44$ & $3 \cdot 03$ \\
\hline Mean & $7 \cdot 56$ & $14 \cdot 23$ & 1.88 & $6 \cdot 67$ \\
\hline SD & 0.94 & $2 \cdot 95$ & 0.28 & $2 \cdot 49$ \\
\hline \multicolumn{5}{|c|}{ (b) Female subjects } \\
\hline 1 & 5.33 & $11 \cdot 02$ & 2.06 & 5.69 \\
\hline 2 & $6 \cdot 10$ & 11.97 & 1.96 & $5 \cdot 87$ \\
\hline 3 & $5 \cdot 96$ & $11 \cdot 37$ & 1.91 & $5 \cdot 41$ \\
\hline 4 & $5 \cdot 36$ & $10 \cdot 01$ & 1.87 & 4.65 \\
\hline 5 & $6 \cdot 61$ & $12 \cdot 38$ & $1 \cdot 87$ & $5 \cdot 77$ \\
\hline 6 & $6 \cdot 03$ & $11 \cdot 18$ & $1 \cdot 85$ & $5 \cdot 15$ \\
\hline 7 & $5 \cdot 39$ & $9 \cdot 89$ & 1.83 & $4 \cdot 50$ \\
\hline 8 & $5 \cdot 28$ & $9 \cdot 54$ & 1.81 & $4 \cdot 26$ \\
\hline 9 & 5.04 & 9.09 & 1.80 & $4 \cdot 05$ \\
\hline 10 & 5.64 & $9 \cdot 74$ & 1.73 & $4 \cdot 10$ \\
\hline 11 & $6 \cdot 20$ & $10 \cdot 60$ & 1.71 & $4 \cdot 42$ \\
\hline 12 & $4 \cdot 68$ & $7 \cdot 78$ & 1.66 & $3 \cdot 10$ \\
\hline 13 & $5 \cdot 75$ & $9 \cdot 33$ & 1.62 & $3 \cdot 58$ \\
\hline 14 & 4.84 & $7 \cdot 59$ & 1.57 & $2 \cdot 75$ \\
\hline 15 & 5.01 & $7 \cdot 51$ & $1 \cdot 50$ & $2 \cdot 50$ \\
\hline 16 & 6.00 & 8.97 & $1 \cdot 50$ & 2.98 \\
\hline Mean & $5 \cdot 58$ & $9 \cdot 87$ & 1.77 & $4 \cdot 30$ \\
\hline SD & 0.56 & 1.49 & $0 \cdot 16$ & $1 \cdot 10$ \\
\hline
\end{tabular}

* Predicted from Food and Agriculture Organization/World Health Organization/United Nations University (1985).

The intensity and duration of the self-reported occupational and discretionary activities of the subjects are shown in Fig. 2. An estimate of the absolute cost of this physical activity plus thermogenesis (both diet-induced and thermo-regulatory) can be obtained by subtracting BMR from TEE for each individual. Since the contribution of thermogenesis is small and relatively constant, TEE-BMR is therefore largely indicative of the energy cost of physical activity. One male subject (no. 1) had an exceptionally high value for TEE - BMR (13.28 MJ/d) which was due to very strenuous manual labour incorporating 


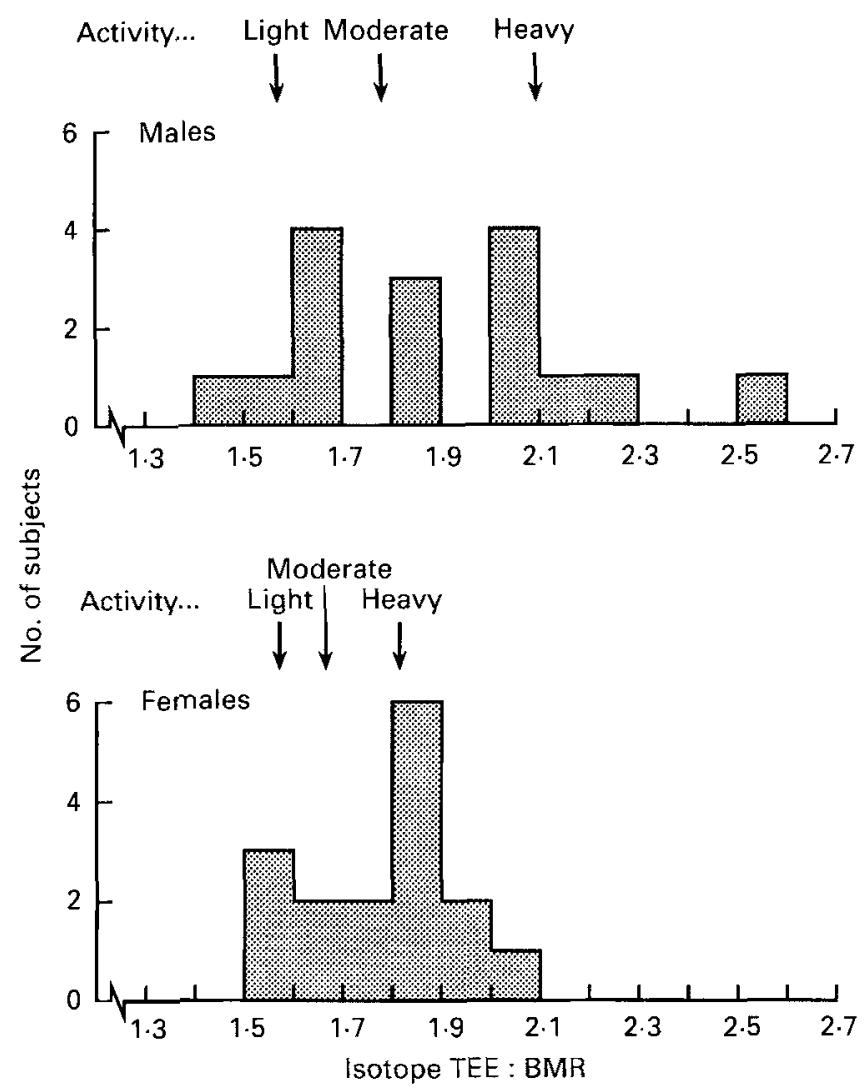

Fig. 1. Distribution of observed energy expenditures of male and female healthy free-living subjects in relation to Food and Agriculture Organization/World Health Organization/United Nations University (1985) recommendations. Energy expenditures (isotope TEE) are expressed as multiples of basal metabolic rate (BMR). For details of experimental procedures, see pp. 146-148.

$12 \mathrm{~h}$ shifts on $6 \mathrm{~d} /$ week together with walking or cycling to and from work. When this subject was excluded, the range of TEE-BMR values was 3 -fold in the men (3.03-9.13 MJ/d, coefficient of variation (CV) $29 \%$ ) and about 2 -fold in the women $(2 \cdot 50-5 \cdot 87 \mathrm{MJ} / \mathrm{d}, \mathrm{CV} 26 \%)$.

These large ranges are clearly inconsistent with the occupational energy demands of most of the subjects and their discretionary activity may, therefore, be as important as occupational activity in predicting energy requirements. When the activity scores for the occupational and discretionary components were combined, there was a high correlation with the measured cost of physical activity in the male subjects $(r 0.790, P<0.01$; Fig. 3$)$ but the two variables were not significantly correlated in the female subjects $(r 0-317)$. Neither occupational nor discretionary activity scores alone were significantly correlated with the measured cost of activity in the male subjects.

The inclusion of leisure-time activity within the total activity pattern is consistent with the range of energy expended on physical activity by the subjects. The actual time spent on discretionary activity averaged $1.9(\mathrm{SD} 0.9) \mathrm{h} / \mathrm{d}$ by the male subjects (range $0.2-4.2 \mathrm{~h} / \mathrm{d}$ ) and by the females averaged $1.8($ SD 0.9$) \mathrm{h} / \mathrm{d}$ (range $0.2-3.6 \mathrm{~h} / \mathrm{d} ;$ Fig. 2). When non-active leisure time is excluded the males $(n 14)$ spent on average $1.2($ SD 0.7$) \mathrm{h} / \mathrm{d}$ (range $0.2-2.3 \mathrm{~h} / \mathrm{d}$ ) on medium to high intensity discretionary activity, mainly active sports such as jogging, 

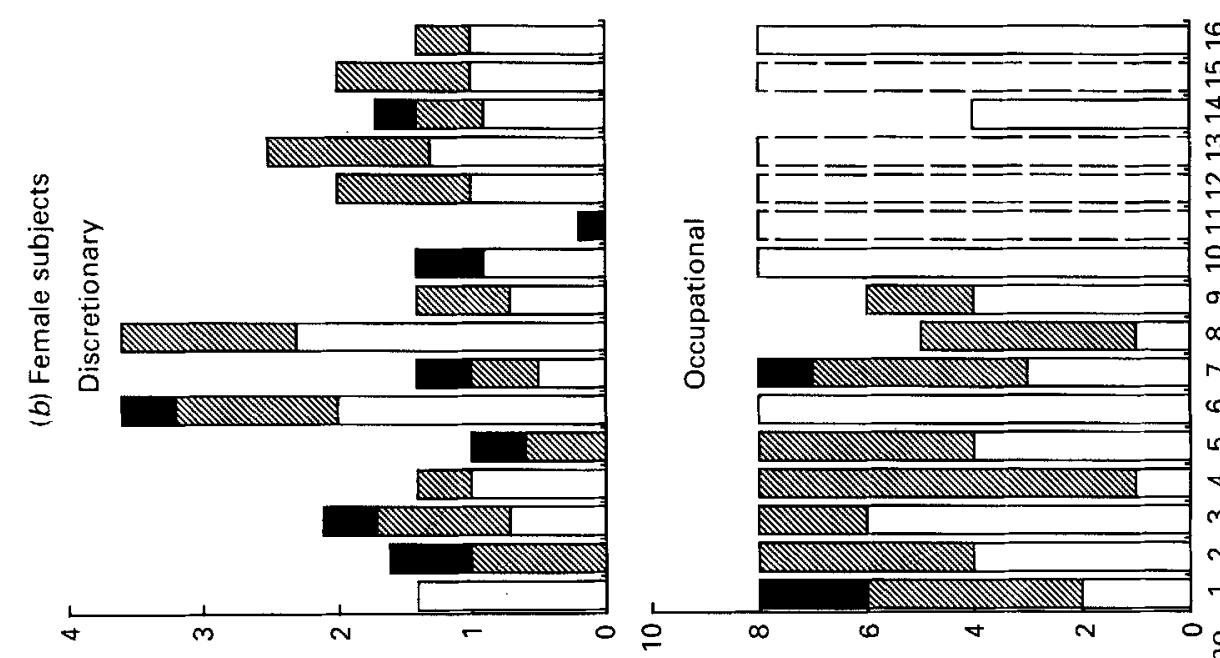

Aep sad sinoy to $\circ \mathrm{N}$
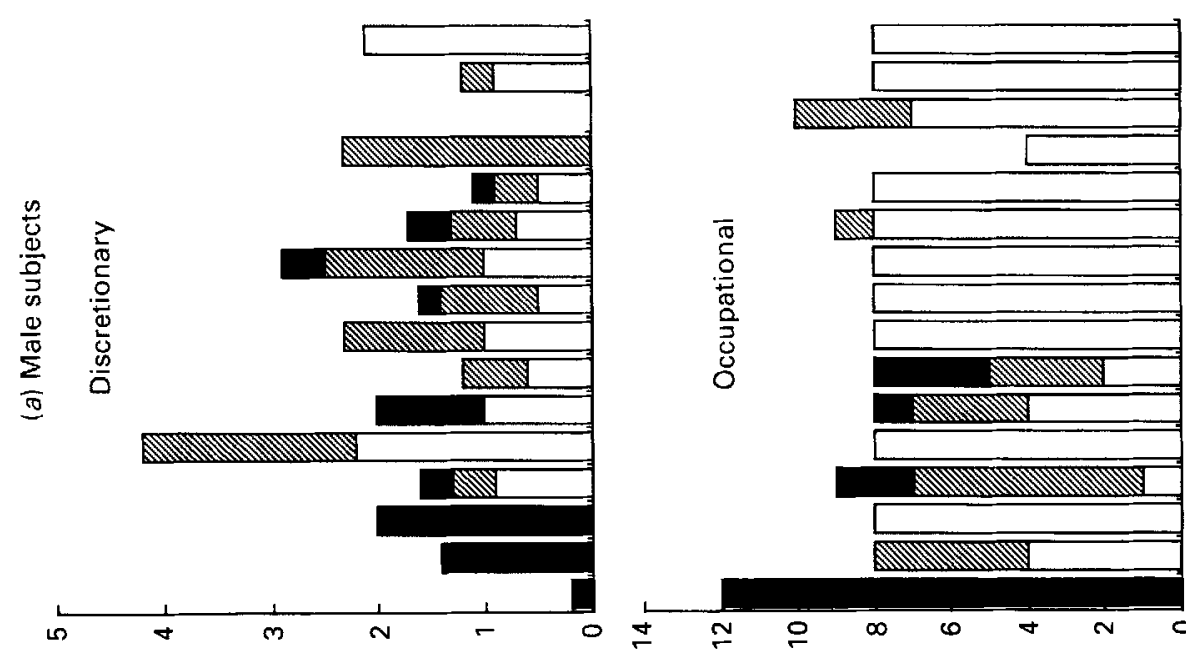

kep גəd sınoy to 'ON 


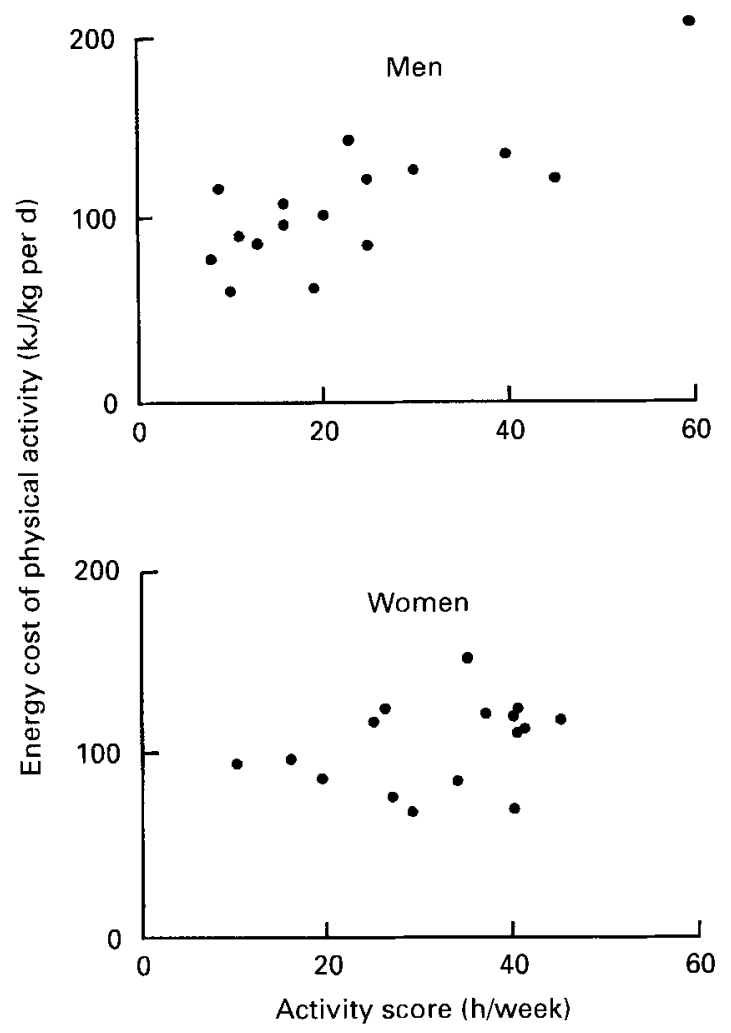

Fig. 3. Relationship between measured energy cost of physical activity ( $\mathrm{kJ} / \mathrm{kg}$ per $\mathrm{d}$ ) and combined activity scores for occupational and discretionary components. Activity scores represent the number of hours per week spent at moderate activity levels.

football, rugby, squash, volleyball and karate. The corresponding values for the females were $0.9(\mathrm{SD} 0.4) \mathrm{h} / \mathrm{d}$ (range $0.2-1.6 \mathrm{~h} / \mathrm{d}$ ). This discretionary activity was also mainly in the form of active sport such as badminton, running, walking for exercise, dancing, aerobics and cycling. Overall the trend was for those in sedentary or semi-sedentary occupations to compensate for low occupational energy demands with regular physical exercise of varying intensities. However, manual workers were not necessarily inactive after work; female manual workers tended to participate in non-active leisure activities, but the male manual workers were inclined to complement the high energy demands of their occupations with active sports activities.

\section{DISCUSSION}

The results of the present study have demonstrated that the usual classification of energy requirements by occupation alone may give a poor prediction of TEE and that it is now essential to combine information from both occupational and discretionary activities. This is supported by the earlier study of Prentice et al. (1985) who observed considerably lower energy expenditure patterns in women from a broadly similar range of social class and occupation as the female subjects in the present study. The only consistently different methodological source of bias in the data sets relates to the DLW isotopic fractionation corrections applied in the earlier study where the $50 \%$ fractionation assumption would underestimate energy expenditure by approximately $5 \%$ compared with the average 


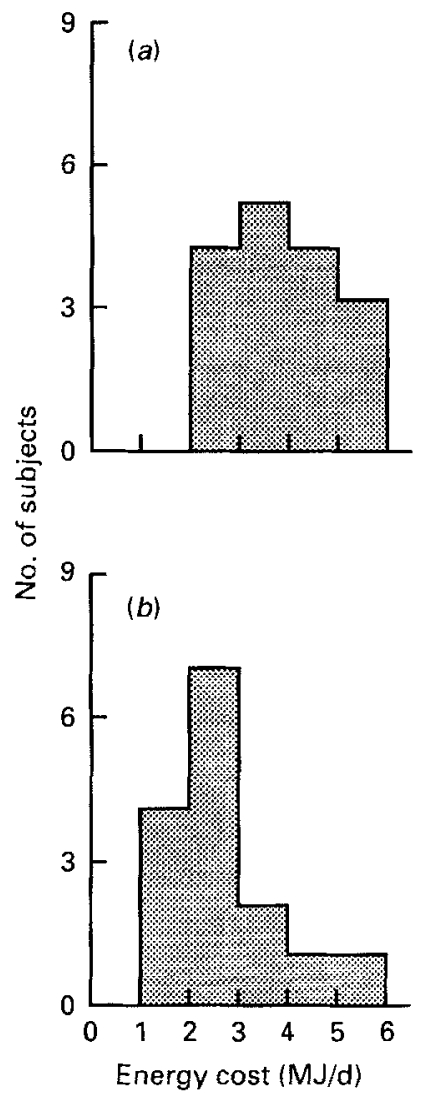

Fig. 4. Comparative distribution of the energy cost of physical activity in female subjects. (a) Northern Ireland, (b) Cambridge (from Prentice et al. 1985).

fractionation correction of $32 \%$ in the present study. However, even when the data sets are compared on the basis of the latter correction factor there remains a significant difference in mean energy expenditure (0.32 times BMR; Fig. 3). Environmental factors such as climate are highly unlikely to have contributed to this difference. Moreover, occupational energy demands could only partly explain this difference, since, with the exception of two subjects whose work involved varying degrees of manual type activity, the majority were in largely sedentary occupations. However, there is a marked contrast in the reported discretionary activities of the subjects; with one exception all subjects in the present study participated in regular physical exercise, often of medium to high intensity, compared with only three subjects in the earlier study.

It is debatable whether the commitment required to achieve the high rates of energy expenditure observed in some of these subjects would be compatible with the lifestyles of many people. Factorial computations of the time and energy cost of accommodating the mean difference (approximately $1.28 \mathrm{MJ}$ ) in energy expenditure on physical activity show that this could be achieved by, for example, $0.5 \mathrm{~h} / \mathrm{d}$ walking at $4.8 \mathrm{~km}$ ( 3 miles $) / \mathrm{h}$ plus $0.5 \mathrm{~h} / \mathrm{d}$ of badminton, swimming, cycling or tennis, plus $1 \mathrm{~h} / \mathrm{d}$ of light gardening or household maintenance tasks (Durnin \& Passmore, 1967). These examples, which include recognition of the desirability of including exercise for promoting cardiorespiratory efficiency, suggest that with the necessary motivation these inputs are feasible, could 
realistically be accommodated in modern lifestyles and would have a significant impact on TEE values. In addition, physical exercise may exert more subtle effects through an enhanced sense of well-being and may even contribute to making people more active generally. To propose more stringent guidelines would probably be inappropriate although clearly the results of the present study show that they are attainable.

It is difficult to propose reasons why the subjects in the present study should be so physically active, particularly since sedentary lifestyles have been postulated as a risk factor for CHD and paradoxically Northern Ireland has one of the highest rates of CHD in the world. However, if physical fitness which may, in part, be genetically determined, is the independent protective factor against CHD then the type rather than the overall pattern of physical activity may be more important in this context (Sobolski, 1987). However, it is conceivable that the study sample was biased by a high proportion of health-conscious subjects since $58 \%$ of invited subjects declined to participate in the study. It could also be speculated that current health statistics, particularly in relation to CHD and recent attempts to promote sport in Northern Ireland, allied to the most extensive leisure centre provision in the $\mathrm{UK}$, has motivated individuals into taking more positive steps to promote fitness levels. The effects of these initiatives on CHD statistics remain to be seen.

In conclusion, the major finding that has emerged from the present study is that superficial changes in lifestyle can have an important impact on energy requirements. Furthermore, the social and health sequelae of volitional leisure-time activity is likely to assume even greater significance in the future as work becomes increasingly sedentary and leisure time increases, concomitant with the trend towards shorter and fewer working days. Consequently the customary definition of energy requirements based entirely on occupational criteria may now be a redundant concept.

This work was supported by the Department of Health and Social Services (Northern Ireland).

\section{REFERENCES}

Barker, M. E., McClean, S. I., McKenna, P. G., Reid, N. G., Strain, J. J., Thompson, K. A., Williamson, A. P. \& Wright, M. E. (1989). Diet, Lifestyle and Health in Northern Ireland. Coleraine: University of Ulster.

Black, A. E., Prentice, A. M. \& Coward, W. A. (1986). Use of food quotients to predict respiratory quotients for the doubly-labelled water method of measuring energy expenditure. Human Nutrition: Clinical Nutrition 40C, $381-391$.

Coward, W. A. (1988). The doubly-labelled-water $\left({ }^{2} \mathrm{H}_{2}{ }^{18} \mathrm{O}\right)$ method: principles and practice. Proceedings of the Nutrition Society 47, 209-218.

Coward, W. A., Roberts, S. B. \& Cole, T. J. (1988). Theoretical and practical considerations in the doublylabelled water $\left({ }^{2} \mathrm{H}_{2}{ }^{18} \mathrm{O}\right)$ method for the measurement of carbon dioxide production rate in man. European Journal of Clinical Nutrition 42, 207-212.

Department of Health and Social Security (1979). Recommended Daily Amounts of Food Energy and Nutrients for Groups of People in the United Kingdom. Report on Health and Social Subjects no. 15. London: H.M. Stationery Office.

Durnin, J. V. G. A. \& Passmore, R. (1967). Energy, Work and Leisure. London: Heinemann Educational Books Ltd.

Food and Agriculture Organization/World Health Organization/United Nations University (1985). Energy and Protein Requirements, Technical Report no. 724. Geneva: World Health Organization.

Metropolitan Life Insurance Company (1983). Metropolitan height and weight tables. Statistical Bulletin, Metropolitan Insurance Company 64, $2-9$.

Prentice, A. M. (1988). Applications of the ${ }^{2} \mathrm{H}_{2}{ }^{18} \mathrm{O}$ technique in free-living adults. Proceedings of the Nutrition Society 47, 259-268.

Prentice, A. M., Black, A. E., Coward, W. A., Davies, H. L., Goldberg, G. R., Murgatroyd, P. R., Ashford, J., Sawyer, M. \& Whitehead, R. G. (1986). High levels of energy expenditure in obese women. British Medical Journal 292, 983-987.

Prentice, A. M., Coward, W. A., Davies, H. L., Murgatroyd, P. R., Black, A. E., Goldberg, G. R., Ashford, J., Sawyer, M. \& Whitehead, R. G. (1985). Unexpectedly low levels of energy expenditure in healthy women. Lancet i, 1419-1422. 
Schoeller, D. A. (1988). Measurement of energy expenditure in free-living humans using doubly labelled water. Journal of Nutrition 118, 1278-1289.

Sobolski, J., Kornitzer, M., de Backer, G., Dramaix, M., Abramowicz, M., Degre, S. \& Denolin, H. (1987). Protection against ischemic heart disease in the Belgian physical fitness study: physical fitness rather than physical activity? American Journal of Epidemiology 125, 601-610.

Weir, J. B. (1949). New methods for calculating metabolic rate with special reference to protein metabolism. Journal of Physiology 109, 1-9. 